\title{
A LOW COST ELECTROSTATICALLY FOCUSED TWT*
}

\author{
1Bernard K. Vancil, FDE Inc., Email: Bernie@fdeassc.com \\ 21070 SW Tile Flat Road, Beaverton, OR 97007; Tel: 503-628-0703; Fax: 503-628-1194 \\ ${ }^{2}$ Edwin G. Wintucky, NASA Glenn Research, Email Edwin.G.Wintucky@grc.nasa.gov
}

Ring-loop circuits are well known for their simplicity, low cost, compactness, low mass, high gain and efficiency and absence of backward wave oscillations. Peak powers over $20 \mathrm{kw}$ have been achieved. They also have low harmonic output and excellent phase performance.

We have developed a double ring-loop circuit that permits electrostatic focusing of an electron beam to at least 0.4 micro pervs. This eliminates the magnet stack and further lowers cost and weight. It permits glass rod fastening of circuit elements as well as gun and collector assemblies, as is done in cathode ray tubes. Using CRT construction techniques, the TWT can be built on automated equipment.

Our application is wireless communications at $2.5 \mathrm{GHz}$ with output power of $100-200$ watts in the linear regime. Unsaturated gain is $40 \mathrm{~dB}$. We have successfully focused an $8.5 \mathrm{KV}$ beam, with current between 160 and $200 \mathrm{ma}$. We estimate the cost of the TWT in quantity production at under $\$ 1,000$. Figure 1 shows the ring-loop elements "in the flat". These are laser cut from .020-inch molybdenum sheet, which is an inexpensive way of fabricating a few circuits. Quantity production is done using a chemical etching process.

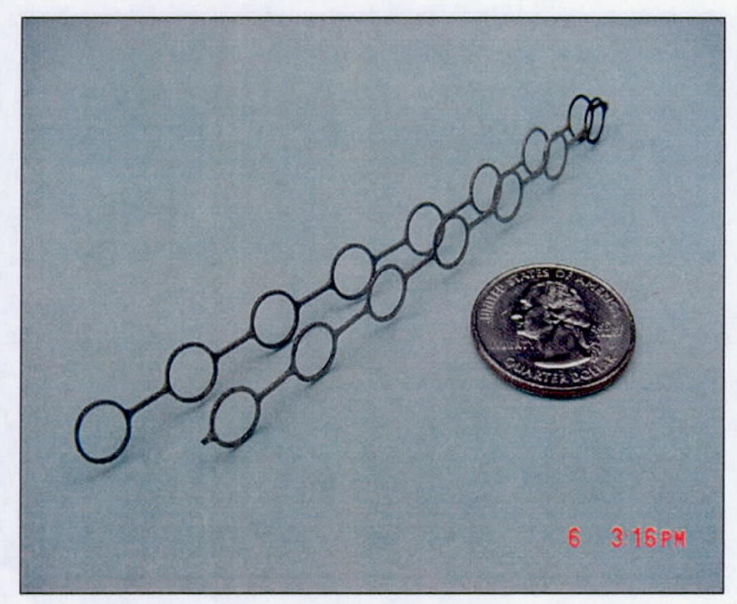

Figure 1

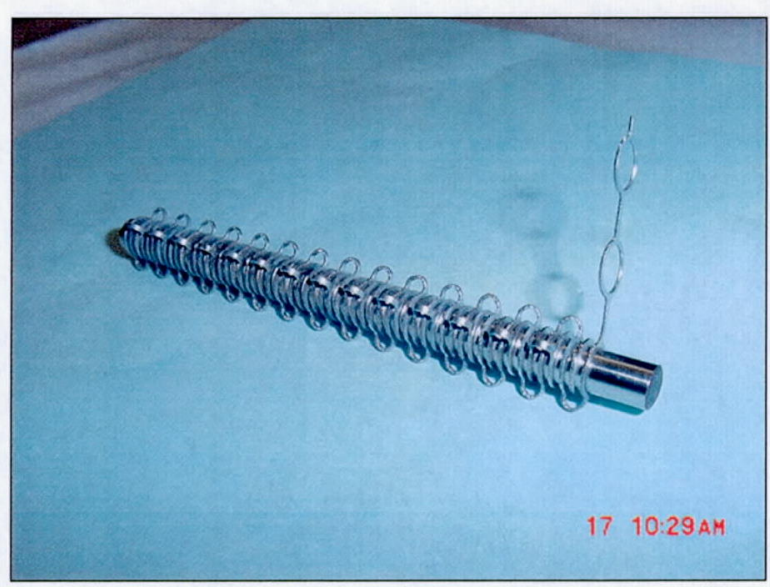

Figure 2

Figure 2 is a photo of the double ring-loop circuit after folding. The two halves are held in relative alignment by a central mandrel. In operation they are held by insulator supports arranged peripherally inside a metal tube. An end view of this arrangement is shown in Figure 3. 


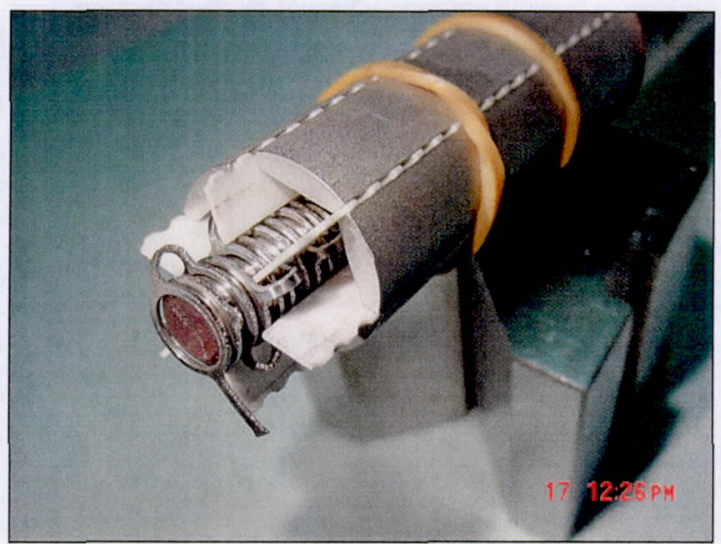

Figure 3

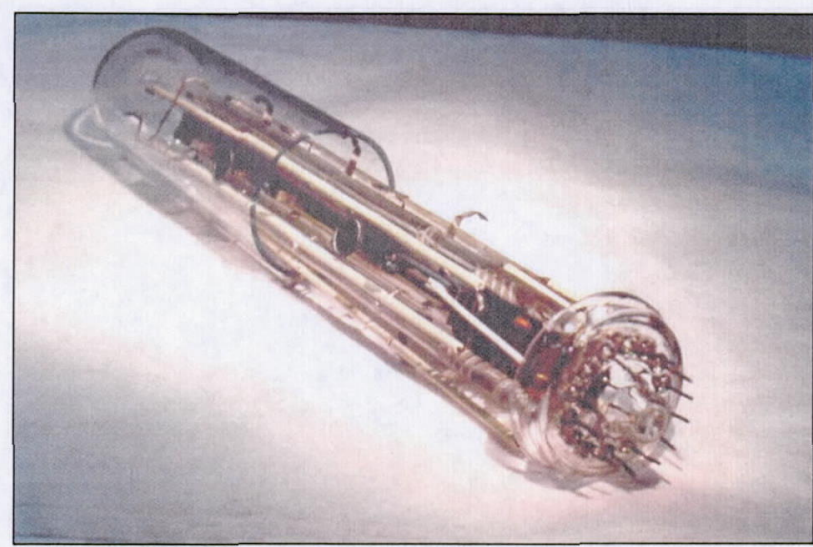

Figure 4

The glass rodded assembly consisting of the gun, 5 stage collector and circuit is shown in Figure 4. Figure 5 shows beam trajectory modeling of a double ring-loop focusing stack. In this case the fields are generated by a series of flat washers, .020 inches thick and .040 inch apart. 5,000 volts are placed between the washers. The trajectory plots show a tendency to form a hollow beam with electrons residing mostly at the $50-60 \%$ radius position relative the inner diameters of washers. This hollow beam tendency in electrostatically focused stacks makes the ring-loop a better choice than the double helix circuit that has been tried in the past. The reason is that beams residing near circuit elements are apt to cause backward wave oscillations in helix tubes. Backward oscillation does not occur in ring-loop circuits and interaction between the beam and circuit is improved.

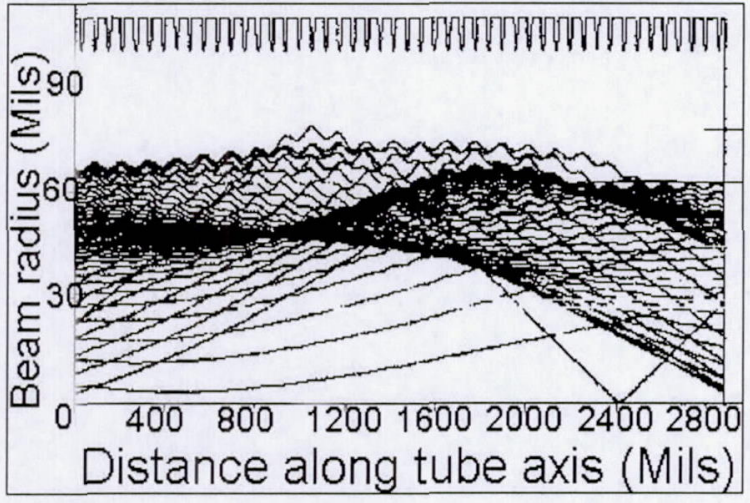

Figure 5

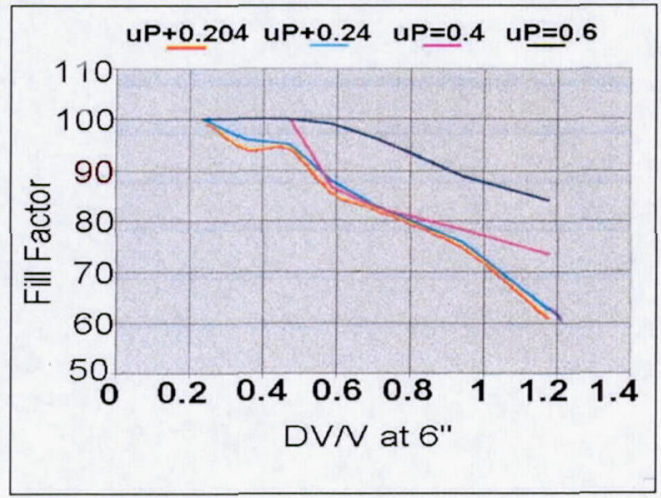

Figure 6

Figure 6 is a plot showing beam tunnel filling factors vs. dV/V, which is the D.C. difference in voltage between ring-loops divided by the average voltage of the rings. Several curves are shown representing different perveances. Clearly focusing becomes more difficult as perveance is raised.

We constructed a beam tester comprising an electron gun, focusing stack, and series of collectors and utilizing CRT construction technology. Focusing of $95 \%$ was achieved for a beam of $8.5 \mathrm{kv}$ and $180 \mathrm{ma}$ of current. The next step is to build a complete tube.

\footnotetext{
* This research is supported by a Small Business Innovation Research grant from NASA Glenn Research Center.
} 